\title{
OPTIMIZATION OF QUALITY IN EXPORTED Polyscias balfouriana "MARGINATA" BY USING DIFFERENT SHADE LEVELS
}

\author{
H.K.S.G.Gunadasa ${ }^{1}$ and P.K.Dissanayake ${ }^{2}$
}

\begin{abstract}
Foliage plant industry in Sri Lanka often has to face difficulties due to problems associated with the qualities of the final product of plant especially, pale green colour leaves and poor quality shoots, which are not accept by the buyers in export market. An investigation was carried out to develop the green colour and other qualities of Polyscias balfouriana "Marginata" (PBM) using different shade levels within 10 weeks. Canes, $10 \mathrm{~cm}$ long were used as planting materials and planted in coir beds under, 55, 60, 65, 70, 75, 80, 85, 90 and 95\% shade levels. Other qualities evaluated for PBM were shoot length, leaf area, number of leaves per shoot. It was evident that the preferable forest green colour was achieved significantly $(p=0.001)$ at the highest shade levels of 85 and $90 \%$. The leaf area of $14 \mathrm{~cm}^{2}$ and, sprout of $7 \mathrm{~cm}$ to $7.5 \mathrm{~cm}$ length also achieved at highest shade levels of $85 \%$ and $90 \%$. Percentage of canes with 3 or more than 3 leaves per shoot was significantly higher than that of canes with less than 3 leaves at shade levels higher than the control. The higher percentage of acceptable canes with 3 or more than 3 leaves was found in shade level of $80 \%, 85 \%$ and $90 \%$. With these findings it can be concluded that the use of high shade levels such as $85 \%$ and $90 \%$ at foliage nurseries are favorable to obtain quality PBM plant for export market.
\end{abstract}

Key Words: Polyscias balfouriana "Marginata”, shade levels, green colour, leaf area, sprout

\section{INTRODUCTION}

Growing ornamental plants such as flowers and foliage plants have developed in to a major agro industry in Sri Lanka during last 2 to 3 decades. Even though floriculture industry in Sri Lanka has a short history, a remarkable progress has been made in the production of high quality ornamental plants with international standards. Country's climatic variations, biodiversity, and, relatively cheap land and labour availability lead to a steady increase in the production of tropical foliage plants for export in Sri Lanka.Polyscias balfouriana "Marginata" $(\mathrm{PBM})$ is a common foliage plant in the world floriculture industry, especially in countries where tropical climate is available. It is a perennial crop, belonging to family Araliaceae. PBM is extensively used in landscaping purposes and also popular as a potted ornamental plant (Bose and Chowdhury, 1991). The morphology of the leaves adds value for its quality to attract consumer especially in the export market. Demand for the PBM in Japan and European countries like Holland, Denmark is very high because of its bushy growth habit.

PBM potted rooted cane is one of the main product that is being exported. Colour of

\footnotetext{
${ }^{1}$ Post Graduate Institute of Agriculture, University of Peradeniya, Peradeniya, Sri Lanka 58

${ }^{2}$ Dept. of Export Agriculture, Faculty of Agricultural Sciences, Sabaragamwa University of Sri Lanka, Belihloya, Sri Lamka
} 
eaves, leaf expansion, shoot elongation and number of leaves in a shoot are the main quality parameters in PBM (Noordegraaf, 1992). As the tropical shade loving plant, it is necessary to consider a proper shade level in nurseries where, PBM are being grown. However, at present no proper shade level is being used by growers in propagating PBM plant for the export market and it leads to produce poor marketable quality plant. Especially, development of pale green colour leaves and poor quality of structure in PBM seems to be a major problem for companies to make best value without rejection in the market.

Among many factors that are affecting the colour development of green leaves of ornamental foliage plants like PBM, light level is a very important factor because it affects the chloroplast development in leaves during the growth (Blackmann, 1956; Ballantine and Forde, 1970; Prasad and Kumar, 2003). Leaf expansion, shoot elongation and number of leaves per shoot are also significantly affected by light intensity (Noordegraaf, 1992). This is in line with the findings of Ballantine and Forde (1970) that the light levels during growth has pronounced effects on chloroplast development. The chloroplast of the shade plants are usually larger, have greater chlorophyll content, a greater proportion of chlorophyll b to chlorophyll a, and a smaller stromal volume than in chloroplasts of high light plants. Prasad and Kumar (2003) noted that increased light absorption is brought about by increased number of chloroplasts and as an adaptation to shade, leaf area of shade loving plants increase significantly.

Also according to Daubenmire (1974) short internodes, less leaf area per plant and later maturation of leaves were resulted with high light intensities.
Even though, many growers at present are using different shade levels to have optimum quality in foliage plant at their own nurseries, there is no adequate information readily available on effective shade levels on development of green colour and development of quality shoots structure of the PBM or other foliage plants under local conditions.

Therefore, this investigation was undertaken using PBM to determine the shade levels well suitable for the optimization of quality of the plant, specially, development of proper green colour and plant structure which is important in securing demand in highly competitive export market. Proper green colour of the PBM in this study was considered as forest green colour according to the Royal Horticulture Society colour chart (Graf, 1982) and other structural characters considered were shoot length, leaf area, and number of leaves per shoot.

\section{MATERIALS AND METHODS}

\section{Location}

The experiment was conducted at nursery field of Serendib Horticulture Technologies (Pvt.) Ltd. Kalagedihena, Sri Lanka. This nursery belongs to low country-wet zone of Sri Lanka (WL3 Agro ecological zone, Gampaha District, Western province). Average solar radiation in the area was $491.66 \mathrm{MJ} / \mathrm{m}^{2}$.

\section{Planting materials and experimental conditions}

Bare rooted hard wood stem cuttings $(10 \mathrm{~cm}$ canes) of PBM were used as planting material. Each cane was potted in $2.5 \mathrm{~cm}$ net pot with sterilized coir dust medium. They were established in coir fiber beds in the propagation unit with $15 \times 10 \mathrm{~cm}$ spacing under a net house with $50 \%$ shade level. The RH was about $76 \%$ during the experimental 
period. Hundred plants were selected for one treatment.

Watering was practiced daily within the 10 weeks experimental period.Chlorophyrophos $40 \%$ EC was applied one month after establishment, to control termite attack. Frequent observations were made and no fertilizer application was done during the experimental period.

\section{Shade levels}

Nine shade levels were selected as treatments such as 50 (control), 55, 60, 65, 70, 75, 80, 85, 90 and 95\%. Black knitted nylon netting was used to provide selected shade levels. The selection of these shade levels mainly based on the preliminary experiment conducted in the nursery. 50\% shade level was used as a control because the nursery management used this shade level to grow foliage plant for a long time.

\section{Assessment of the effect of shades on cane quality parameters}

Light intensities were recorded daily, using photometer (200,000 lux), inside and outside the nets. Shoot elongation was recorded every week using a measuring tape. Shoot length of $7 \mathrm{~cm}-7.5 \mathrm{~cm}$ was considered as acceptable length for export. In every other week, leaf expansion was measured using the grid method and $14 \mathrm{~cm}^{2}$ leaf area was considered as export standard. Royal Horticulture Society colour chart (Graf, 1982) was used to record the colour of leaves. Forest green, Meadow green, Shamrock green, Fresh green and pale green were recorded in all matured leaves of potted canes and Forest green and Meadow green were considered as acceptable colours, whereas rest of the colors were not. The canes with 3 or more than 3 leaves per shoot were selected as accepted plants for export market and canes less than 3 leaves per shoot were rejected. Number of leaves counted on randomly selected 20 canes in each shade level.

\section{Chlorophyll extraction and chlorophyll content}

Chlorophyll extraction was done using $80 \%$ acetone (MacKinney, 1941 and Arnon, 1949). Standard equations were used for calculating chlorophyll contents on the basis of light absorption of Spectrophotometer at $663 \mathrm{~nm}$ and $645 \mathrm{~nm}$.

\section{Statistical analysis}

The results were statistically analyzed by SAS statistical software (SAS Inst.,USA) (The count data analysis method was applied to analyze this data)

\section{RESULTS AND DISCUSSION}

\section{Effect of shade levels on shoot elongation of PBM canes}

The plants treated with the highest shade levels $80 \%, 85 \%$ and $90 \%$ recorded the most rapid increment in shoot length than low shade levels. Shoot length gradually increased after 2 weeks of planting (Figure 01). The height of shoot that required for export market is $7 \mathrm{~cm}-7.5 \mathrm{~cm}$ in $10 \mathrm{~cm}$ canes. Required shoot height was obtained in $80 \%, 85 \%$ and $90 \%$ shade levels within 10 week period. The increase in level of shade decreased the time taken to increase the shoot length.

The results revealed that the $85 \%$ and $90 \%$ shade levels brought shoot length to $7 \mathrm{~cm}-$ $7.5 \mathrm{~cm}$ within 8 weeks after planting and plants under $80 \%$ shade levels reached it at 9 weeks after planting. Shade levels below $80 \%$ did not reach $7 \mathrm{~cm}$ levels even in 10 weeks after planting. According to Daubenmire (1974) short internodes resulted with high light intensities and present findings are also in line with those findings. 
Even though collectively there were no significant differences of shoot length between shade levels, more number of canes found with shoot length more than $7 \mathrm{~cm}$ under $75 \%, 80 \%, 85 \%, 90 \%$ and $95 \%$ shade levels in 10 weeks of planting whereas in control very few. Therefore it is obvious that at least to avoid losses in the market by having high shade levels; nursery management can have more plants with acceptable shoot length.

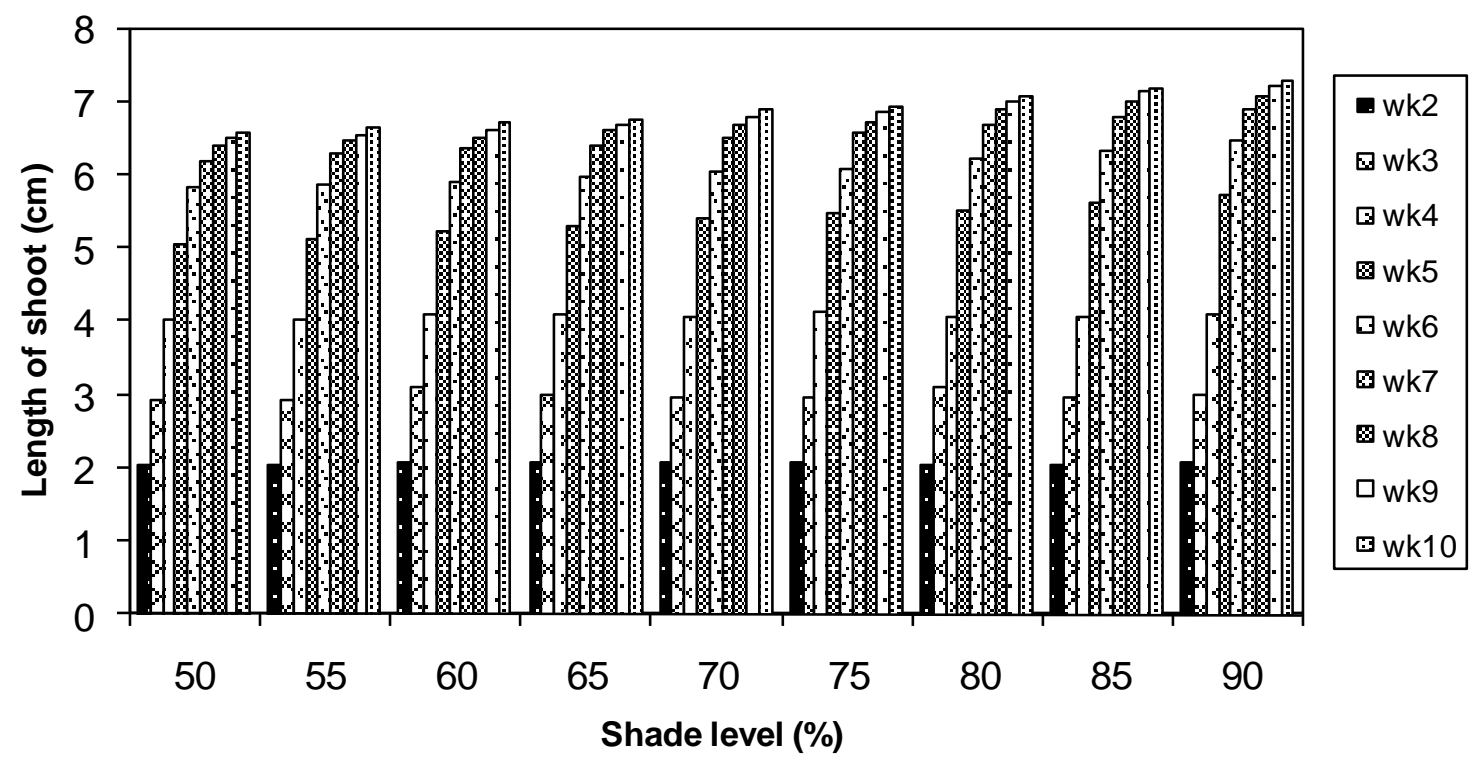

Figure 01. Changes of shoot length of Polyscias balfouriana "Marginata" (in cm) under different levels of shades during 10 weeks period

\section{Effect of shade levels on leaf expansion of PBM canes}

Normal size of leaf area with export quality was defined as around $14 \mathrm{~cm}^{2}$. According to the results gained from grid method, leaf area increased as shade level increased (Figure 02). The required size of leaf area was resulted in $85 \%$ and $90 \%$ shade levels by 10 weeks after planting. It was found that adaptation to shade increase leaf area in a way that minimizes the use of metabolites (for example, by increasing leaf area at the expense of photosynthate allocation to root growth), and decrease in the amount transmitted and reflected light. Shade leaves are thinner but larger in surface area than sun leaves (Prasad and Kumar, 2003) and less leaf area was resulted with high light intensities (Daubenmire, 1974), the results of

the present study were also according to these phenomenon.

\section{Effect of shade levels on green colour of PBM leaves}

The significant $(p=0.001)$ enhancement of leaf green colour to Forest green and Meadow green was observed in the canes treated with $85 \%$ and $90 \%$ shades than that of the control treatment (50\% shade level). The colour development was more prominent in $10^{\text {th }}$ week of planting. The 
highest number of pale green colour leaves was observed on the canes under $50 \%$ shade levels. The intermediate colours between forest green colour and pale green color was obtained under $55 \%, 60 \%, 65 \%, 70 \%, 75 \%$, $80 \%$ shade levels (Figure 03 ). The $85 \%$ and $90 \%$ shade levels were the most reliable light level to have forest green colour of PBM leaves. Chlorophyll content of forest green colour level 1 and 2 is higher than other levels (Figure 04).

\section{Chlorophyll content}

Content of chlorophyll a, chlorophyll b, and total chlorophyll were increased with increasing level of green colour (Figure 04).

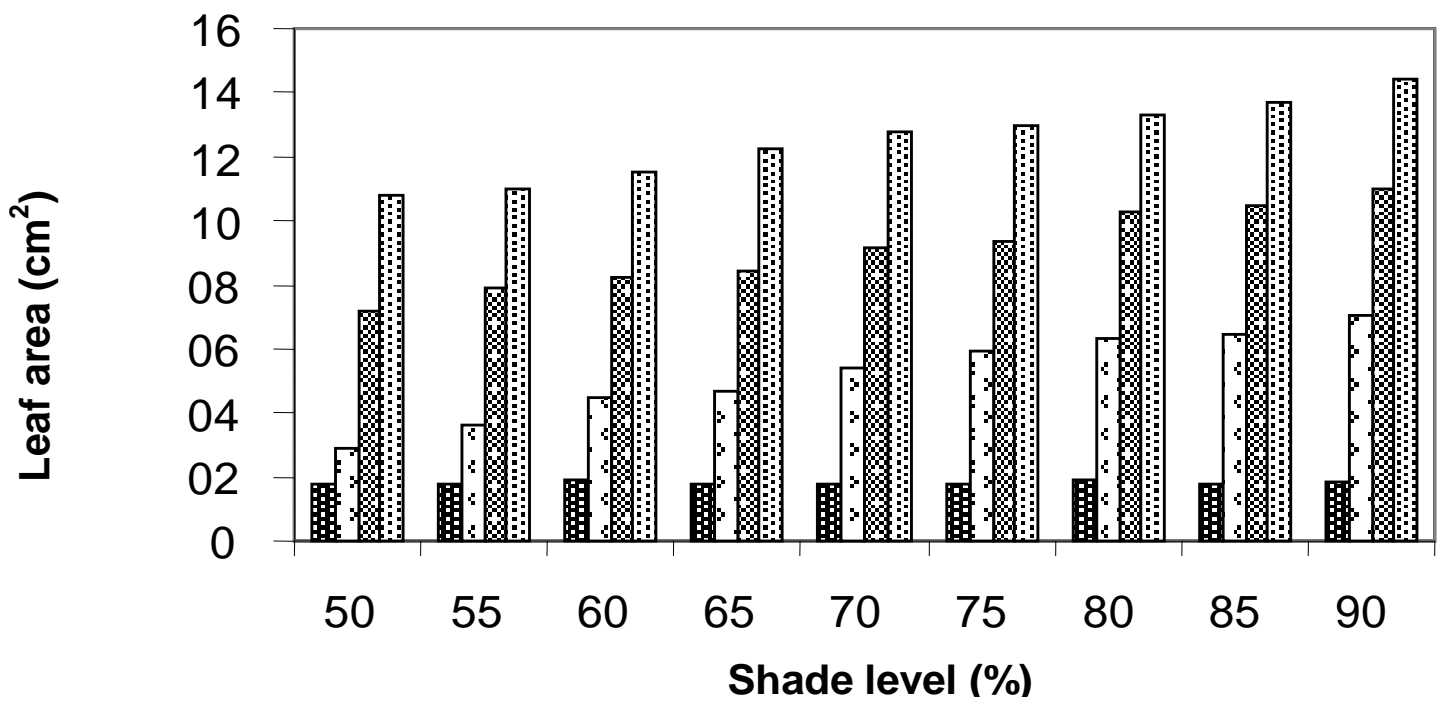

Figure 02: Changes of leaf expansion of Polyscias balfouriana "Marginata" (in $\mathbf{c m}^{2}$ ) under different levels of shade during 10 weeks of planting

According to Ballantine and Forde (1970) the light level during growth has pronounced effects on chloroplast development. The chloroplast of the shade plants are usually larger, have greater chlorophyll content (Baru, 1961), a greater proportion of chlorophyll b to chlorophyll a, and a smaller stomata volume than chloroplasts of high light plants (Ballantine and Forde (1970).

Prasad and Kumar (2003) noted that, increased light absorption is brought about by increased number of chloroplasts, which is accompanied by a lowered concentration of other pigments that interfere with the light absorption process. In addition, there is 
sometimes a change in the orientation of the chloroplasts so that the broad dimension is oriented toward the light.Resistance to chlorophyll degradation in shade plants serves to increase chlorophyll concentration.
Therefore it is true that the colour development is the reason of synthesis of more chlorophyll $\mathrm{a}$ and $\mathrm{b}$ in the leaves of PBM and the chlorophyll content increased as increasing shade level.

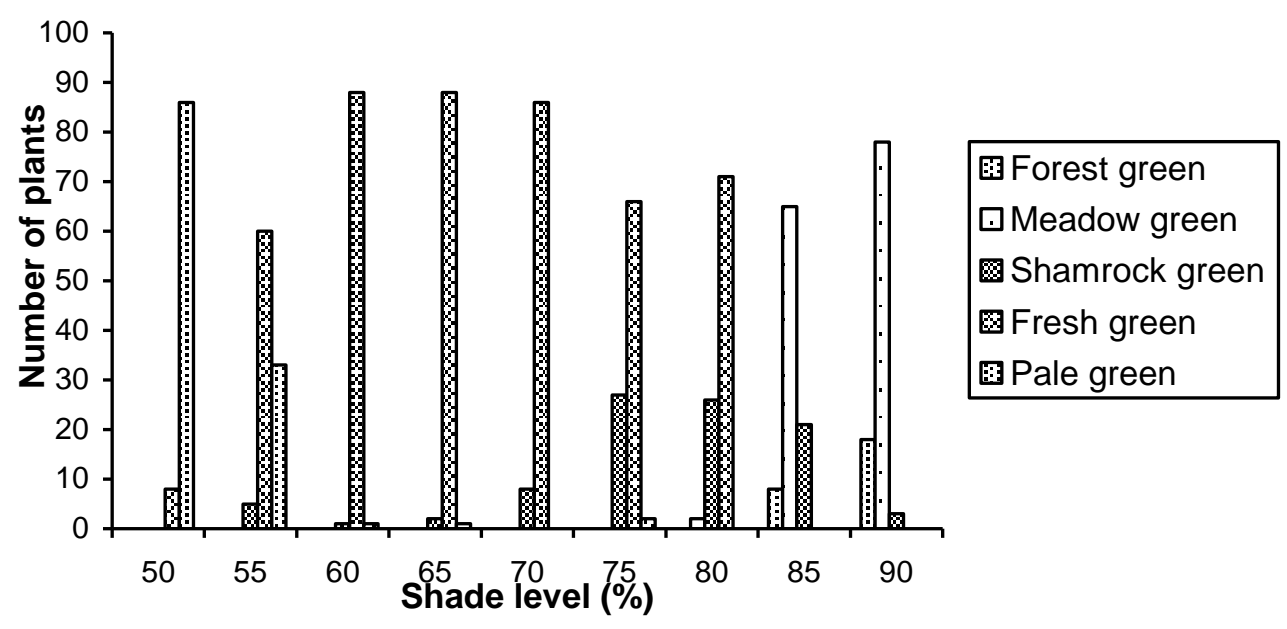

Figure 03 : Number of Polyscias balfouriana "Marginata" plants at different levels of green colour leaves under different levels of shades within 10weeks of planting. Level 1-Forest green colour, Level 2-Meadow green colour, Level 3- Shamrock green colour, Level 4- Fresh green colour, Level 5-Pale green colour (Graf, 1982)

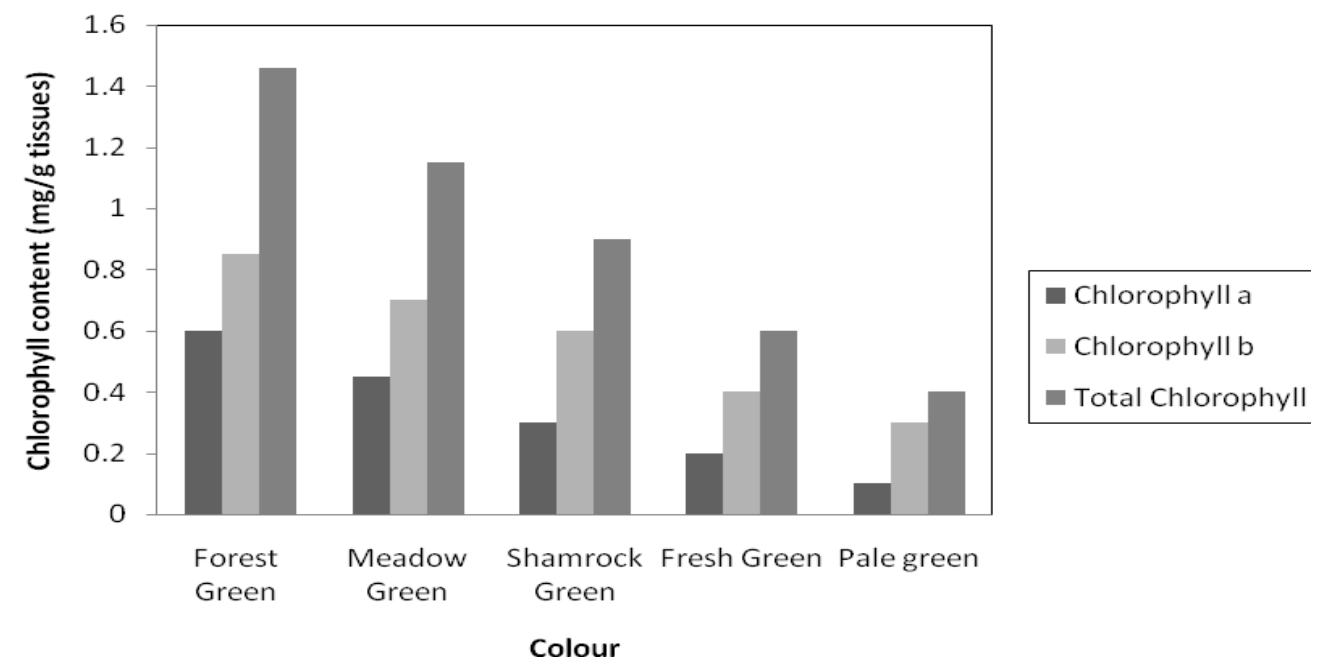

Figure 04: Chlorophyll a, chlorophyll b and total chlorophyll content in Polyscias balfouriana "Marginata" leaves at different levels of colour. 
Shade levels and number of leaves per shoot

The acceptable plant percentage was determined referring to the quality specifications given by buyers in foreign market. The major factors considered for separation were shoot length $(7-7.5 \mathrm{~cm}$ length), leaf area ( $14 \mathrm{~cm}^{2}$ or more), colour of leaves (Forest green colour or Meadow green colour) and the number of leaves per shoot (3 or more than 3 leaves per shoot). The canes, which were not fulfilling all these requirements, were rejected. Figure 05 shows percentage of canes with 3 or more than 3 leaves per shoot and less than that.

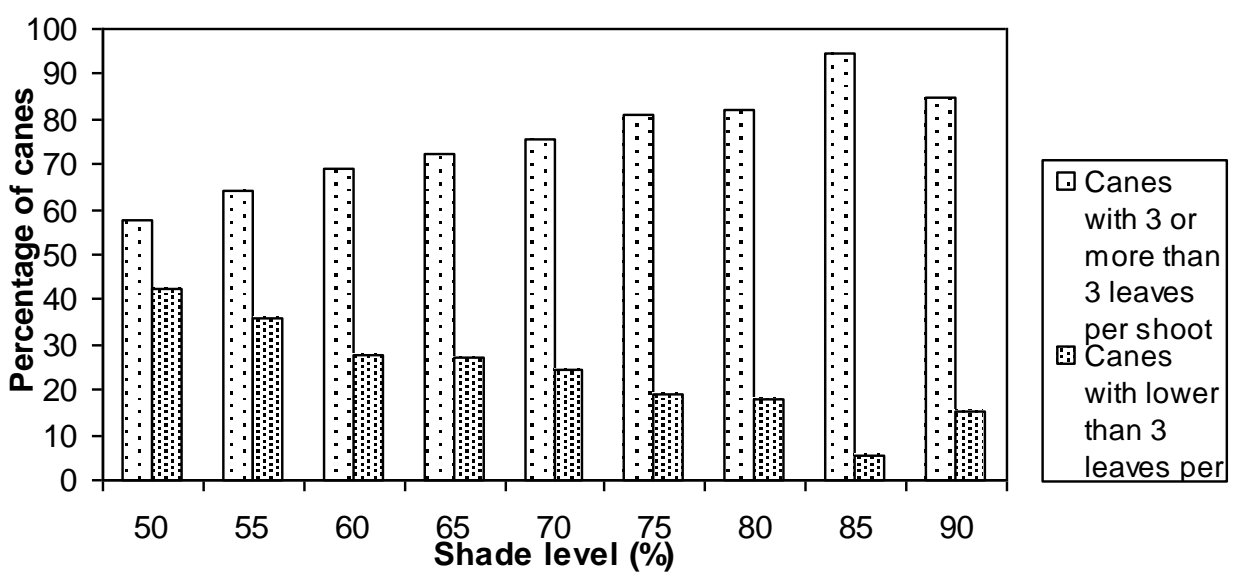

Figure 05: Percentage of Polyscias balfouriana "Marginata" plants with 3 or more than 3 leaves per shoot and lower than 3 leaves per shoot, under different shade levels

The percentage of canes with 3 or more than 3 leaves per shoots were significantly higher than that of canes with low number of leaves under different shade conditions $(\alpha=0.05)$. The highest accepted percentage was observed in canes treated with $85 \%$ shade level and the lowest accepted percentage found at 50\% (control shade level) after 10 weeks of planting. The canes treated with 90\% shade level showed a slight reduction of accepting percentage than $85 \%$ shade level.
According to the overall results of the study, PBM maintained good export quality under shade levels those were higher than recommended shade level $(50 \%)$ utilized in the experiment. However, shade levels, where which lowest rejection percentage is recorded are important for exporting companies to have extra profit. 


\section{CONCLUSIONS}

Therefore it can be concluded that shade levels at $85 \%-90 \%$ completely help to obtain PBM plants with maximum quality standard within 10 weeks. Nevertheless lower number of canes under rejection considering all the quality characters can be achieved with plant grown under high shade levels such as $85 \%$ and $90 \%$ is more advantages to nursery management to have profit.
Although this study concluded that the effectiveness of shade levels in increasing export quality of PBM plant in field conditions, a full scale commercial evaluation is needed to recommend these treatments to commercial floricultural industries.

\section{REFERENCES}

Arnon, D.I. (1949). Copper enzymes in isolated chloroplasts. Polyphenoloxidase in Beta vulgaris. Plant physiology. 24: 1-15.

Ballantine, J.E.and Forde, B.J. (1970).The effect of light intensity and temperature on plant growth and chloroplast ultrastructure in soybean. American Journal of Botany, 57, 1150-9.

Baru. D.N. (1961). Effect of shade and shade trees. Two and A Bud. 8(4): pp 4-12.

Blackmann, G.E. (1956). Influence of light and temperature on leaf growth. In. F.L. Milthorpe Ed), The growth of leaves, London, Butterworths Scientific Publications, pp. 151-169.

Bose, T.K. and Chowdhury, B. (1991). Tropical garden plants, Horticulture and Allied Daubenmire, R.F. (1974). The Light Factor. Plants and Environment, 3rd ed, John Willey and Sons Inc. 211-239.

Graf, A.B. (1982). Exotica Series 4 International: Pictorial Cyclopedia of Exotic Plants Tropical and Near-Tropic Regions (Vol.2.). Roehrs Co. Publishers, U.S.A.

MacKinney, G. (1941). Absorption of Light by Chlorophyll Solutions. Journal of Biological Chemistry. 140: 315-322.

Noordegraaf, C. (1992). Production and Marketing of High Quality Plants. International Work shop on Floriculture and Nursery Industries and Environment. ISHS Acta Horticulture 353.

Prasad, S. and Kumar, U. (2003). Stress Physiology of Horticultural Crops. Principles of Horticulture, Agrobios, 191-193. 